\title{
Multi-Benzocyclobutene Functionalized Silane for Low- $k$ Polyarylsilane Thermosets with Low Coefficient of Thermal Expansion and High Thermostability
}

Yuanrong Cheng*, Jing Cai, Junyi Li, Xueliang Wu, Yunfei Shi, Jun Wang

Department of Materials Science, Fudan University, 220 Handan Road, Shanghai 200433, People's Republic of China.

Email: chengyr@fudan.edu.cn* 


\section{EXPERIMENTAL SECTION}

\section{Materials}

4-BrBCB (97\%) was purchased from Chem-target Technologies Co. Ltd. Extra dry ethyl ether was refluxed over and distilled from sodium/benzophenone immediately prior to use. N-butyl lithium (n-BuLi), dichlorodiphenylsilane $\left(\mathrm{SiPh}_{2} \mathrm{Cl}_{2}\right)$, phenyltrichlorosilane $\left(\mathrm{SiPhCl}_{3}\right)$, tetrachlorosilane $\left(\mathrm{SiCl}_{4}\right)$ were used as received.

\section{Characterization}

${ }^{1} \mathrm{H}$ NMR, and ${ }^{13} \mathrm{C}$ NMR measurements were recorded on a Bruker DRX-500 Spectrometer with TMS as the reference and $\mathrm{CDCl}_{3}$ as a solvent. Fourier transform infrared (FT-IR) spectra were obtained with a Bruker VERTEX 70 FTIR spectrophotometer with 32 scans at a resolution of $4 \mathrm{~cm}^{-1}$. Differential scanning calorimetry (DSC) was conducted with a TA Q200 calorimeter. Thermogravimetric analysis (TGA) was performed on a TA Q500 at a heating rate of $10^{\circ} \mathrm{C} \cdot \mathrm{min}^{-1}$ under a nitrogen purge rate of $50 \mathrm{~mL} \cdot \mathrm{min}^{-1}$. Dynamic mechanical analysis (DMA) was carried out on a TA Instruments Q800 by the three-point bending mode at a heating rate of 3 ${ }^{\circ} \mathrm{C} \cdot \mathrm{min}^{-1}$ with the test frequency at $1 \mathrm{~Hz}$. The CTE was measured using a TMA Q400 thermomechanical analyzer in the expansion mode at the heating rate of $5{ }^{\circ} \mathrm{C} \mathrm{min}^{-1}$. Dielectric property was investigated by the parallel-plate capacitor method with an Keysight E4980A precision LCR meter and Agilent 16451B as test fixture via the noncontact method in a range of frequencies from $10 \mathrm{k} \mathrm{Hz}$ to $1.2 \mathrm{MHz}$ at room temperature.

\section{Preparation of tetra(benzocyclobutene-4-yl) silane $\left(\mathrm{SiB}_{4}\right)$}


In a $100 \mathrm{~mL}$ three-necked round-bottom flask equipped with a reflux condenser under nitrogen protection, a solution of $3.36 \mathrm{~g} 4 \mathrm{BrBCB}(18.3 \mathrm{mmol})$ in anhydrous diethyl ether (20 mL) was stirred at $-78^{\circ} \mathrm{C}$ followed by dropwise addition of $8.1 \mathrm{~mL}$-butyl lithium (2.5 $\mathrm{M}$ in hexane, $20.3 \mathrm{mmol}$ ) over a period of $10 \mathrm{~min}$. The resulting mixture was stirred for $1 \mathrm{~h}$ at $-78^{\circ} \mathrm{C}$, and then $0.50 \mathrm{~mL} \mathrm{SiCl} 4(4.36 \mathrm{mmol})$ was added dropwise. The mixture was gradually raised to room temperature and was stirred for further 2 hours. $20 \mathrm{~mL}$ deionized water was added cautiously into the system to quench. The solvent was removed by reduced pressure distillation, and the head product was washed with methanol, then recrystallized in petroleum ether to obtain $\mathrm{SiB}_{4}$ as white powders. Yield: 75\%. Melting point (test by DSC): $179{ }^{\circ} \mathrm{C} .{ }^{1} \mathrm{H}$ NMR (500 MHz, $\left.\mathrm{CDCl}_{3}, \delta\right): 3.18(\mathrm{~d}$, 16H), 7.04(d, 4H), 7.22(s, 4H), 7.40(d, 4H).

\section{Preparation of tris(benzocyclobutene-4-yl) phenyl silane $\left(\mathrm{SiPB}_{3}\right)$}

In a $100 \mathrm{~mL}$ three-necked round-bottom flask equipped with a reflux condenser under nitrogen protection, a solution of $3.54 \mathrm{~g} 4 \mathrm{BrBCB}(19.3 \mathrm{mmol})$ in anhydrous diethyl ether $(20 \mathrm{~mL})$ was stirred at $-78^{\circ} \mathrm{C}$ and treated with $8.5 \mathrm{~mL}$ solution of n-butyl lithium (2.5 $\mathrm{M}$ in hexane, $21.25 \mathrm{mmol}$ ). The resulting mixture was stirred at $-78{ }^{\circ} \mathrm{C}$ for $1 \mathrm{~h}$, and then $1.0 \mathrm{~mL} \mathrm{SiPhCl}$ (6.24 mmol) was added dropwise. The mixture was gradually raised to room temperature and stirred for another 2 hours. $20 \mathrm{~mL}$ deionized water was added cautiously into the system to quench. The solvent was removed by reduced pressure distillation, and the head product was washed with deionized water and methanol, then recrystallized in petroleum ether to give $\mathrm{SiPB}_{3}$ as white powders. Yield: 
77\%. Melting point: $106{ }^{\circ} \mathrm{C} .{ }^{1} \mathrm{H}$ NMR $\left(500 \mathrm{MHz}, \mathrm{CDCl}_{3}, \delta\right): 3.18(\mathrm{~d}, 16 \mathrm{H}), 7.04(\mathrm{~d}, 4 \mathrm{H})$, 7.22(s, 4H), $7.40(\mathrm{~d}, 4 \mathrm{H})$.

\section{Preparation of bis(benzocyclobutene-4-yl) diphenylsilane $\left(\operatorname{SiP}_{2} \mathbf{B}_{2}\right)$}

In a $100 \mathrm{~mL}$ three-necked round-bottom flask equipped with a reflux condenser under nitrogen protection, a solution of $3.19 \mathrm{~g} 4 \mathrm{BrBCB}(17.4 \mathrm{mmol})$ in anhydrous diethyl ether (20 mL) was stirred at $-78^{\circ} \mathrm{C}$ and treated with $7.74 \mathrm{~mL}$ solution of n-butyl lithium $(2.5$ $\mathrm{M}$ in hexane). The resulting mixture was stirred at $-78{ }^{\circ} \mathrm{C}$ for $1 \mathrm{~h}$, and then 1.76 $\mathrm{mLSiPh}_{2} \mathrm{Cl}_{2}(8.34 \mathrm{mmol})$ was added dropwise. The mixture gradually raised to room temperature and was further stirred for 2 hours. $20 \mathrm{~mL}$ deionized water was added cautiously into the system to stop the reaction. The solvent was removed by reduced pressure distillation, and the head product was washed with deionized water and methanol, then recrystallized in petroleum ether to give $\mathrm{SiP}_{2} \mathrm{~B}_{2}$ as white crystals. Yield: 82\%. Melting point: $122{ }^{\circ} \mathrm{C} .{ }^{1} \mathrm{H}$ NMR $\left(500 \mathrm{MHz}, \mathrm{CDCl}_{3}, \delta\right): 3.18(\mathrm{~d}, 8 \mathrm{H}), 7.06(\mathrm{~d}$, 2H), 7.22(s, 2H), $7.35(\mathrm{t}, 4 \mathrm{H}), 7.40(\mathrm{t}, 4 \mathrm{H}), 7.56(\mathrm{~d}, 4 \mathrm{H})$.

\section{Bulk polymerization of the monomers}

For preparing bulk BCB silane thermosets, monomers placed in the glass molds were melted at the temperature above the corresponding melting point and degassed in vacuum oven for $0.5 \mathrm{~h}$, and then heated stepwise at $190{ }^{\circ} \mathrm{C} / 1 \mathrm{~h}, 210{ }^{\circ} \mathrm{C} / 1 \mathrm{~h}, 230{ }^{\circ} \mathrm{C} / 1$ $\mathrm{h}, 250{ }^{\circ} \mathrm{C} / 0.5 \mathrm{~h}, 270{ }^{\circ} \mathrm{C} / 1 \mathrm{~h}, 290{ }^{\circ} \mathrm{C} / 0.5 \mathrm{~h}$ and finally $350{ }^{\circ} \mathrm{C} / 0.5 \mathrm{~h}$ under $\mathrm{N}_{2}$ atmosphere. After cooling down to room temperature, the thermosets were removed from the glass molds and polished as transparent rectangular bars for DMA test. 


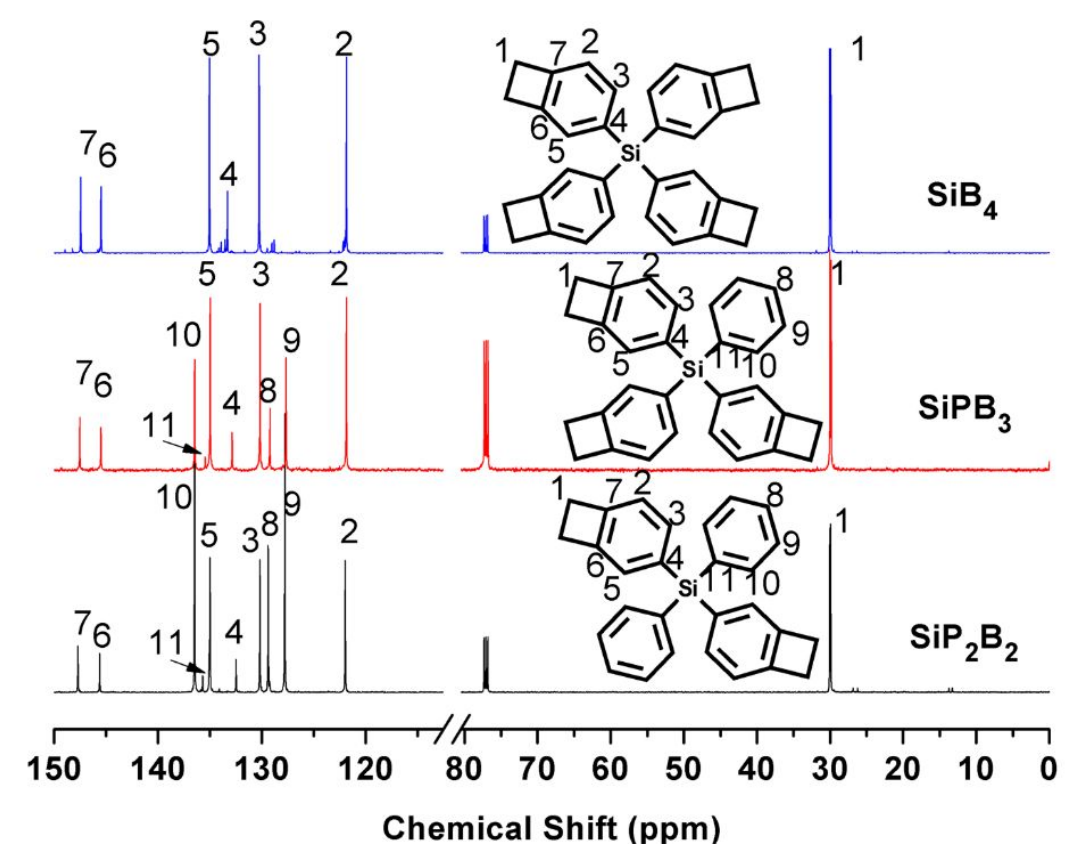

Figure S1. ${ }^{13} \mathrm{C}-\mathrm{NMR}$ spectra of the multi-BCB silane monomers.

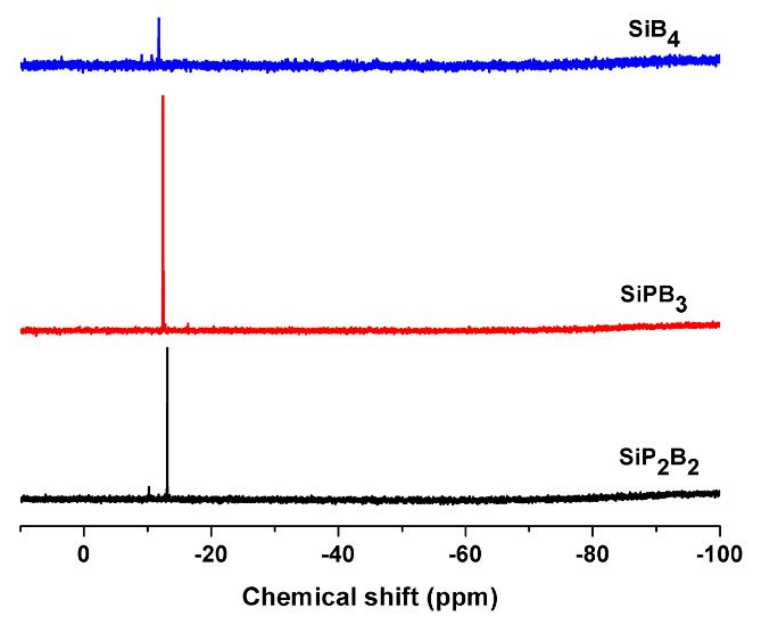

Figure S2. ${ }^{29} \mathrm{Si}$ spectra of the multi-BCB silane monomers. 


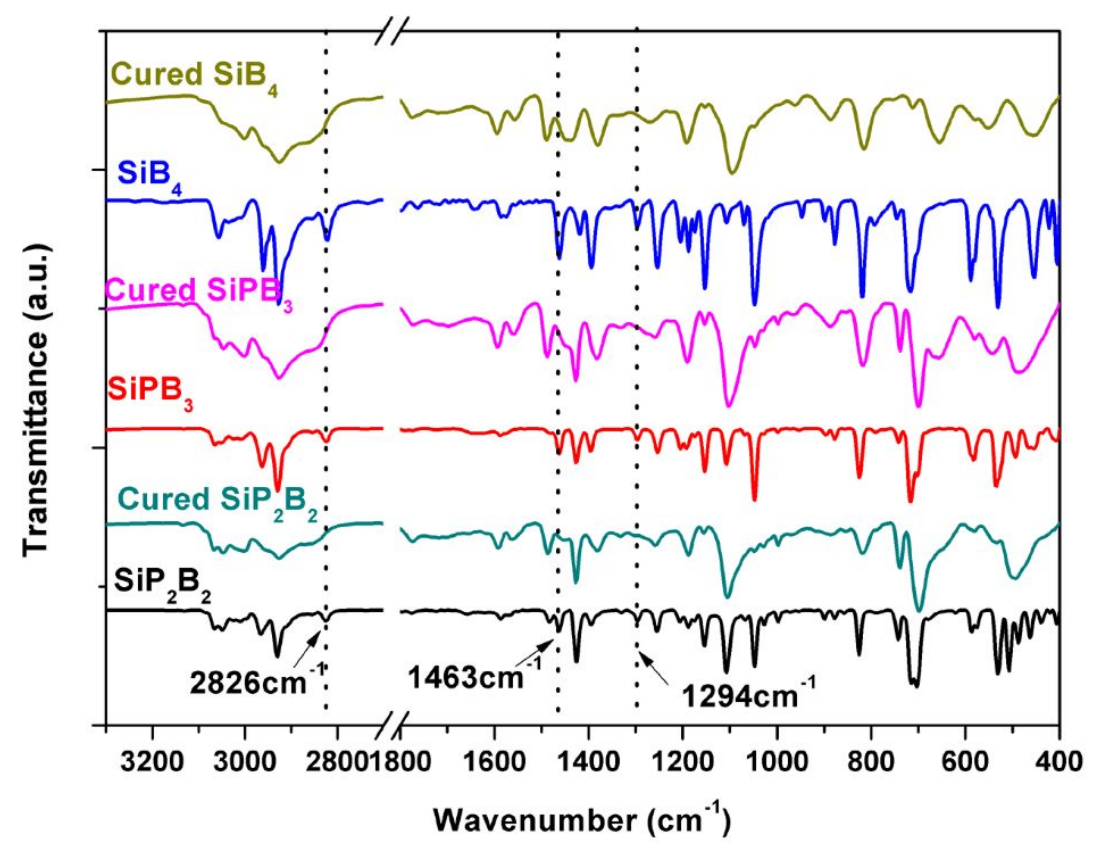

Figure S3. FTIR curves of the multi-BCB silane monomers and the related cured resins.

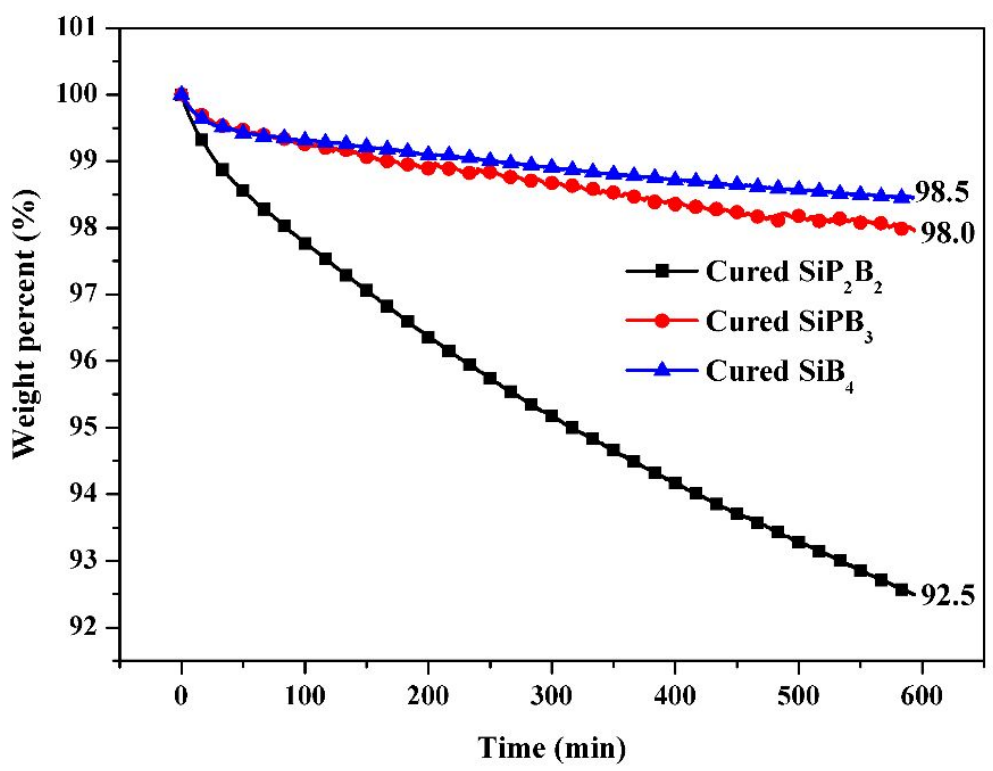

Figure S4. Isothermal TGA of BCB polymers at $350{ }^{\circ} \mathrm{C}$ in $\mathrm{N}_{2}$. 